\title{
Analysis of the Indentation Size Effect in the Microhardness Measurements in $\mathrm{B}_{6} \mathrm{O}$
}

\author{
Ronald Machaka, ${ }^{1}$ Trevor E. Derry, ${ }^{2}$ Iakovos Sigalas, ${ }^{1}$ and Mathias Herrmann ${ }^{3}$ \\ ${ }^{1}$ DST/NRF Centre of Excellence in Strong Materials, School of Chemical and Metallurgical Engineering, \\ University of the Witwatersrand, Johannesburg, Private Bag 3, Johannesburg 2050, South Africa \\ ${ }^{2}$ DST/NRF Centre of Excellence in Strong Materials and School of Physics, University of the Witwatersrand, Johannesburg, \\ Private Bag 3, Johannesburg 2050, South Africa \\ ${ }^{3}$ Fraunhofer Institute for Ceramic Technologies and Systems, Winterbergstra_e 28, 01277 Dresden, Germany
}

Correspondence should be addressed to Ronald Machaka, ronald.machaka@wits.ac.za

Received 9 February 2011; Accepted 13 April 2011

Academic Editor: Paul Munroe

Copyright ( $) 2011$ Ronald Machaka et al. This is an open access article distributed under the Creative Commons Attribution License, which permits unrestricted use, distribution, and reproduction in any medium, provided the original work is properly cited.

The Vickers microhardness measurements of boron suboxide $\left(\mathrm{B}_{6} \mathrm{O}\right)$ ceramics prepared by uniaxial hot-pressing was investigated at indentation test loads in the range from 0.10 to $2.0 \mathrm{kgf}$. Results from the investigation indicate that the measured microhardness exhibits an indentation load dependence. Based on the results, we present a comprehensive model intercomparison study of indentation size effects (ISEs) in the microhardness measurements of hot-pressed $\mathrm{B}_{6} \mathrm{O}$ discussed using existing models, that is, the classical Meyer's law, Li and Bradt's proportional specimen resistance model (PSR), the modified proportional specimen resistance model (MPSR), and Carpinteri's multifractal scaling law (MFSL). The best correlation between literature-cited load-independent Vickers microhardness values, the measured values, and applied models was achieved in the case of the MPSR and the MFSL models.

\section{Introduction}

With hardness values reported to range between $24 \mathrm{GPa}$ and $45 \mathrm{GPa}[1,2]$, boron suboxide $\left(\mathrm{B}_{6} \mathrm{O}\right)$ is sometimes considered to be the third hardest material after only diamond (from $\sim 70$ to $\sim 100 \mathrm{GPa})$ and cubic boron nitride $(\sim 60 \mathrm{GPa})$ [2]. The boron-rich icosahedral ultrahard material belongs to the $\alpha$-rhombohedral boron type structure (R $\overline{3} \mathrm{~m}$ ) [2] which is similar to those of other ultrahard boron-rich materials namely boron carbide $\mathrm{B}_{4} \mathrm{C}$ [3], aluminium magnesium boride $\mathrm{AlMgB}_{14}[4]$, and the newly synthesized boron subnitride $\mathrm{B}_{13} \mathrm{~N}_{2}$ [5].

$\mathrm{B}_{6} \mathrm{O}$ exhibits a rather unusual and wide range of superior properties; among these are high hardness with low density, high mechanical strength, and high chemical inertness $[2,6]$. Along with the other boron-rich ultrahard materials, the potential applications of $\mathrm{B}_{6} \mathrm{O}$ have been an object of intense interest in recent years [2]. However, despite the intensive research efforts, the commercial applications are yet to be realized partly because of (a) the low fracture toughness of polycrystalline $\mathrm{B}_{6} \mathrm{O}[7]$ and considerable practical challenges in the densification of that material $[2,6,7]$ by hotpressing, (b) stoichiometric $\mathrm{B}_{6} \mathrm{O}$ samples that are not easy to synthesize [1,2], (c) poor crystallinity [1, 7], and hence (d) numerous mechanical properties of the material that are still poorly understood [8]-indentation size effect (ISE) in microhardness measurements is one such property.

Until now, the investigation of the mechanical properties of $\mathrm{B}_{6} \mathrm{O}$ by indentation has been neglected in favour of the improvement of densification and fracture toughness of the composites $[2,6,7]$. The hardness reported for the material by different workers often remains a topic of debate, with literature-cited values varying from $24 \mathrm{GPa}$ to $45 \mathrm{GPa}$. To the best of our knowledge, the indentation load-size dependence in the microhardness of hot-pressed $\mathrm{B}_{6} \mathrm{O}$ is being comprehensively examined for the first time in this paper. The aim of this paper is twofold: (1) to report experimental data on the microhardness of hot-pressed $\mathrm{B}_{6} \mathrm{O}$ determined by Vickers pyramidal indentation and (2) to critically examine the ISE phenomenon by means of a comprehensive intermodel 
comparison of various approaches and models proposed in the literature. The nature and the origins of ISE are investigated and discussed.

\section{Materials and Experimental Method}

$\mathrm{B}_{6} \mathrm{O}$ powder was prepared by the reaction of $\mathrm{B}$ and $\mathrm{B}_{2} \mathrm{O}_{3}$ as detailed by Andrews et al. in [9] that were uniaxially hotpressed in $h \mathrm{BN}$ pots under argon environment at $1800^{\circ} \mathrm{C}$ and $50 \mathrm{MPa}$ for 20 minutes. The hot-pressed compacts were then metallographically prepared using a method prescribed by Machaka et al. in [10]. The density of the hot-pressed compacts measured $2.44 \mathrm{~g} / \mathrm{cm}^{3}$. The polished samples were analyzed for phase composition using X-ray diffraction, with $\mathrm{Cu} \mathrm{K}_{\alpha}$ radiation. The powder diffraction patterns were collected using the Bragg-Brentano backscattering geometry over a $10^{\circ}-90^{\circ} 2 \theta$ range, with a $0.02^{\circ}$ step size.

The measurements were performed at room temperature by a Future-Tech microhardness tester at different applied test load between 0.1 and $2.0 \mathrm{kgf}$. At least ten hardness measurements were carefully taken for each load at different locations on the middle of each sample, and the average values were taken as the hardness of the sample at that load. The Vickers indentation impressions were observed using optical microscopy.

\section{Results}

3.1. XRD Measurements. Figure 1 shows the full profile Xray powder diffraction pattern measured on the starting hotpressed $\mathrm{B}_{6} \mathrm{O}$ samples. The diffraction pattern is characteristic of a nominally pure polycrystalline $\mathrm{B}_{6} \mathrm{O}$. All the dominant diffraction peaks can be perfectly indexed to the XRD pattern of $\mathrm{B}_{6} \mathrm{O}$ (JCPDS File Card no. 31-210) reported elsewhere [9]. The lattice parameters, $a=5.39 \AA$ and $c=12.34 \AA$, obtained from XRD analysis are in good agreement with the single crystal data [2].

3.2. Microindentation Measurements. To investigate ISE, microindentation measurements were conducted at test load between 0.1 and $2.0 \mathrm{kgf}$ using a Vickers diamond indenter. Apparent Vickers microhardness values $H_{v}$ were calculated at each load using the conventional approach shown in:

$$
H_{v}=\frac{1.8544 \cdot P}{d^{2}},
$$

where $d$ is the average diagonal length of the Vickers indentation impressions and $P$ is the indentation test load in kgf. Figure 2 shows the dependence of the measured Vickers microhardness of hot-pressed $\mathrm{B}_{6} \mathrm{O}$ on the applied indentation load. Each of the plotted data point is an average of at least ten measurements at each applied test load. The insert in Figure 2 depicts an optical micrograph of a typical Vickers indentation impression.

Evidently, the Vickers hardness is a function of the applied load at low applied indentation test load. The existence of ISE makes it unsatisfactory here to quote a single hardness value when Vickers hardness is used for material

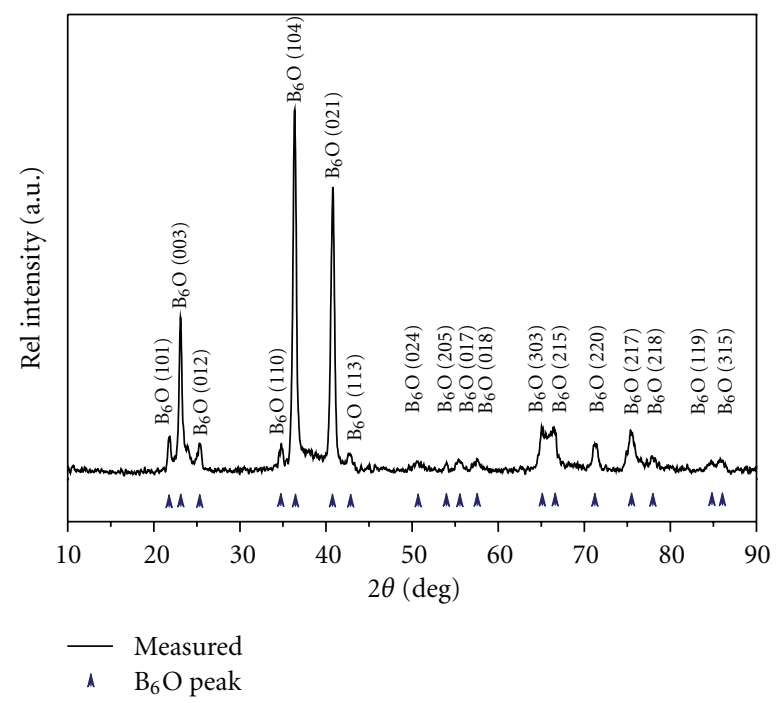

Figure 1: The powder diffraction pattern of a sample of hot-pressed $\mathrm{B}_{6} \mathrm{O}$ showing the predominance of the $\mathrm{B}_{6} \mathrm{O}$ crystalline phase.

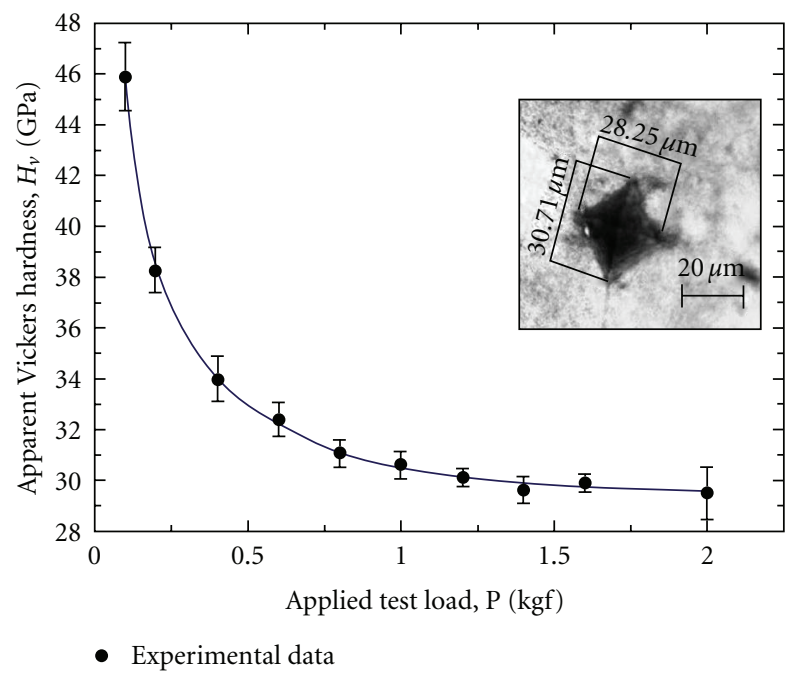

Figure 2: The dependence of apparent Vickers microhardness of hot-pressed $\mathrm{B}_{6} \mathrm{O}$ with applied load. The figure insert shows the optical micrograph of a typical Vickers indentation impression.

characterization. By observation, at applied indentation test loads $\gtrsim 1 \mathrm{kgf}$, a single load-independent Vickers hardness value of $30.0 \mathrm{GPa}$ seems to exists. The load-independent hardness is also sometimes deemed the intrinsic or "true" hardness. The observed value is consistent with literature reported values $[1,2,11]$.

3.2.1. Meyer's Law. The classical power law shown in (2a), also known as the Meyer's law, is frequently used to indicate the existence of ISE for ceramic and other materials [12]. $B$ is a power-fit constant, and the exponent $n$ is the Meyer's 


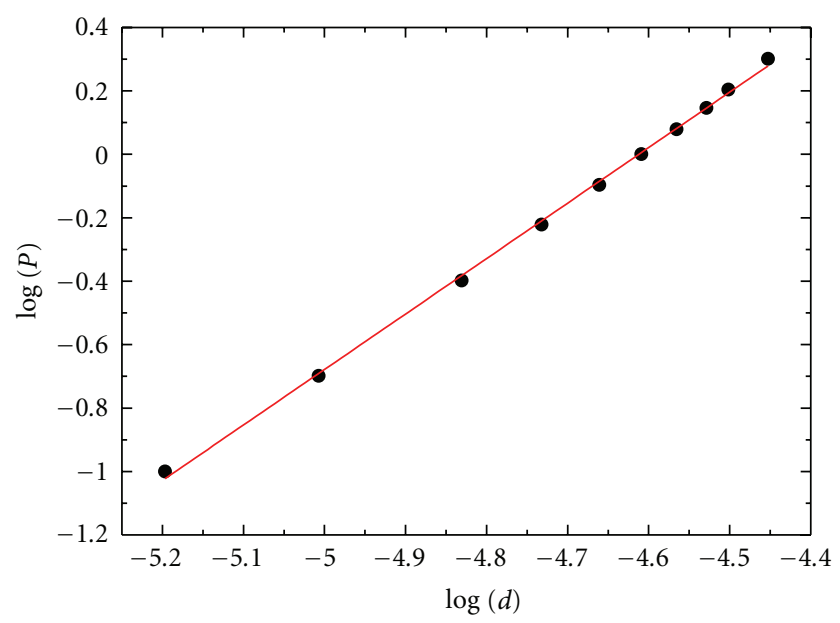

- $\log (P)$ versus $\log (d)$

Linear fit of $\log P$

FIgURe 3: Linear regression analysis of $\log P$ against $\log$ of the indentation diagonal length, $d$ according to the Meyer's law (2b).

index, also known as the size-effect index. The Meyer's index is generally used as a measure of ISE:

$$
\begin{gathered}
P=B \cdot d^{n}, \\
\log P=\log B+n \cdot \log d .
\end{gathered}
$$

The regression analysis of the experimental data using $(2 b)$ is shown in Figure 3. The slope of the linear fit is the Meyer's index, and observed to be $n=1.75$. When $n=2$, the microhardness is expected to be independent of the applied load. However, $n \leq 2$ indicates the existence of an ISE trend, the measured microhardness decreasing with applied load $[13,14]$.

3.2.2. PSR Model. Several studies [14, 15] agree that the Meyer law is probably insufficient to describe the origin of the ISE, although it is a good indicator of its existence. According to Li and Bradt [14], the applied indentation load is related to the average indent diagonal length through a polynomial relationship (3a):

$$
\begin{aligned}
P & =a_{1} \cdot d+a_{2} \cdot d^{2} \\
& =a_{1} \cdot d+\frac{H_{\mathrm{psr}}}{1.8544} \cdot d^{2} .
\end{aligned}
$$

The parameters $a_{1}$ and $a_{2}$ are constants for a given material. The parameters are related to the elastic and the plastic deformation properties of the test material, respectively. The parameter $a_{1}$ is a measure of the surface effects during microhardness indentation which is directly related to the ISE contribution, whilst $a_{2}$ is directly related to the loadindependent microhardness value $H_{\mathrm{psr}}$ as demonstrated in (3b).

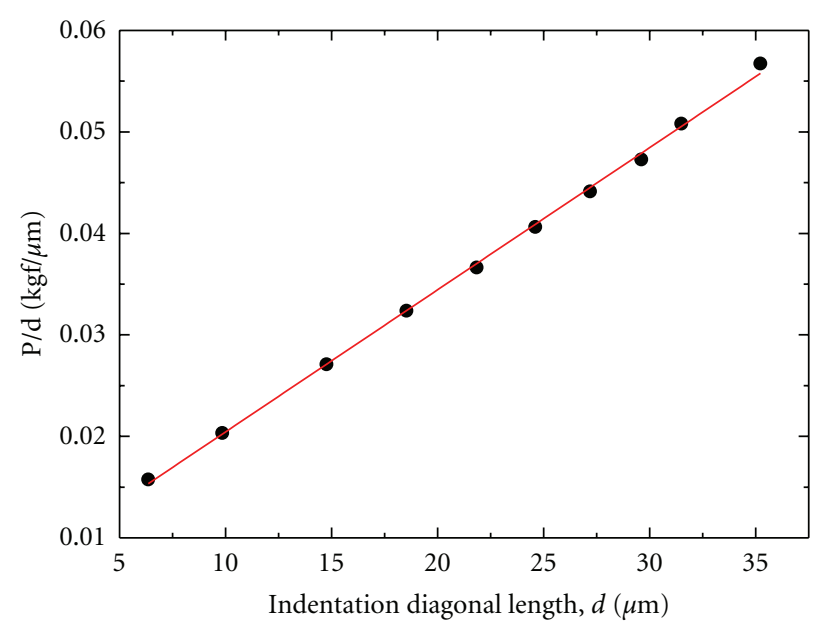

$-\quad P / d$ versus $d$
$-\quad$ PSR model

FIgURE 4: A plot of $P / d$ against $d$ constructed from the experimentally measured data and a best linear fit of the plot.

From (3a), a plot of $P / d$ against $d$ can be constructed to yield a straight line, where best-fit parameters $a_{1}$ and $a_{2}$ can easily be obtained by regression analysis. As shown in Figure 4, a plot of $P / d$ against $d$ is significantly linear, implying that (3a) gives an indication of the existence of ISE in hot-pressed $\mathrm{B}_{6} \mathrm{O}$.

As noted previously, the PSR analysis can be extended to determine $H_{\mathrm{psr}}$ directly from $a_{2}$ using (3b). In this study $H_{\mathrm{psr}}$ was found to be $26.8 \pm 0.3 \mathrm{GPa}$.

3.2.3. Modified PSR Model. Gong et al. in [16] modified the PSR model to investigate the ISE behaviour in various materials. The resulting MPSR model is defined by (4a):

$$
\begin{aligned}
P & =a_{0}+a_{1} \cdot d+a_{2} \cdot d^{2} \\
& =a_{0}+a_{1} \cdot d+\frac{H_{\mathrm{psr}}}{1.8544} \cdot d^{2},
\end{aligned}
$$

where $a_{0}$ is a constant related to the residual surface stresses associated with the surface grinding and polishing processes during sample preparation. The parameters $a_{1}$ and $a_{2}$ are constants as defined in the PSR model (refer to Section 3.2.2). The values of $a_{0}, a_{1}$, and $a_{2}$ can be evaluated by plotting the $P$ data against $d$. The plot of $P$ versus $d$ (and polynomial curve fitting thereof according to the MPSR model) is shown in Figure 5.

As is the case for the PSR model, a load-independent hardness value, $H_{\mathrm{mpsr}}$, can be determined directly from bestfit value of $a_{2}$ from Figure 5 using (4b). In this study, $H_{\mathrm{mpsr}}$ was found to be $28.2 \pm 0.9 \mathrm{GPa}$.

The estimated best-fit values of the $a_{0}, a_{1}$, and $a_{2}$ parameters corresponding $H_{\text {mpsr }}$ values are listed in Table 1. The residual surface stresses contribution to the observed ISE is negligible compared to the contribution of bulk material's plastic deformation characteristics. 


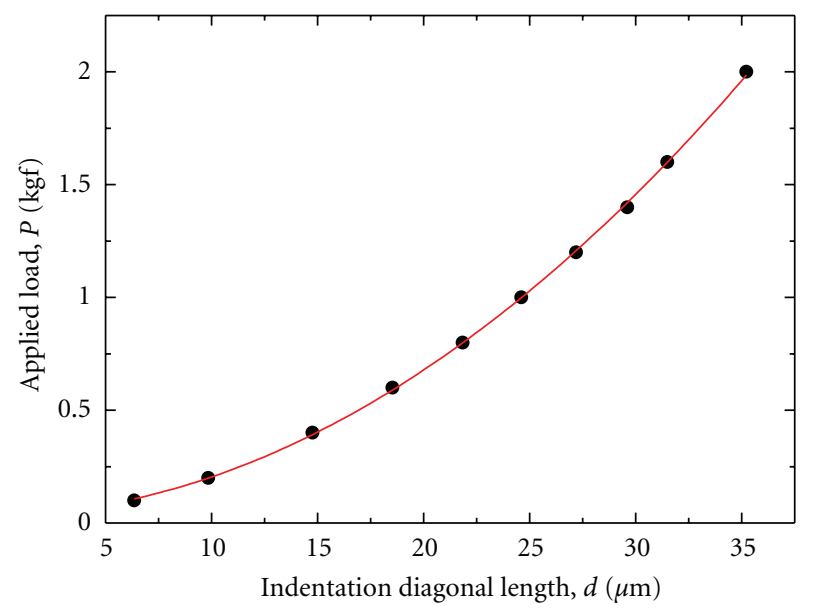

- Experimental data MPSR

Figure 5: A plot of $P$ versus $d$, and curve fitting thereof, according to the MPSR model.

TABLE 1: A summary of the best-fit parameters calculated according to the PSR and MPSR models.

\begin{tabular}{lcccc}
\hline & $a_{0}$ & $a_{1}$ & $a_{2} \times 10^{11}$ & $H(\mathrm{GPa})$ \\
Model & & & & \\
\hline PSR & - & 19711 & 6.95 & $26.8 \pm 0.3$ \\
MPSR & 0.0026 & 20591 & 7.99 & $28.2 \pm 0.9$ \\
\hline
\end{tabular}

The PSR and MPRS parameters estimated by regression analysis are summarized in Table 1. Based on the values and their physical significance according to the energy-balance relation [17], we suggest that the residual surface stresses' contribution $\left(a_{0}\right)$ to the observed ISE is negligible compared to the contribution of bulk material's indentation elastic recovery $\left(a_{1}\right)$ and the indenter/specimen interface friction resistance coupled with elastic resistance of the specimen and the mixed elastic/plastic deformation response of material $\left(a_{2}\right)$.

3.2.4. MFSL Approach. As illustrated in Figure 2, the variation of microhardness with indentation load is a twoparameter problem exhibiting at least two totally different size-dependent regimes: a load-dependent regime and a load-independent regime. The variation of microhardness with indentation load in other words exhibits self-similarity; that is, by observing the property in different scales, a similar, but not exactly the same structure, is obtained-a property of multifractals.

According to Carpinteri and Puzzi in [18], ISE in materials follows the multifractal scaling law shown in (5). However, the indentation size effect property is observed to vanish in the limit of the applied load tending to infinity. From the later, an asymptotic value of hardness which resembles a load-independent or intrinsic value can be determined as illustrated in Figure 6. In this study, we apply the multifractal scaling law in the analysis of observed

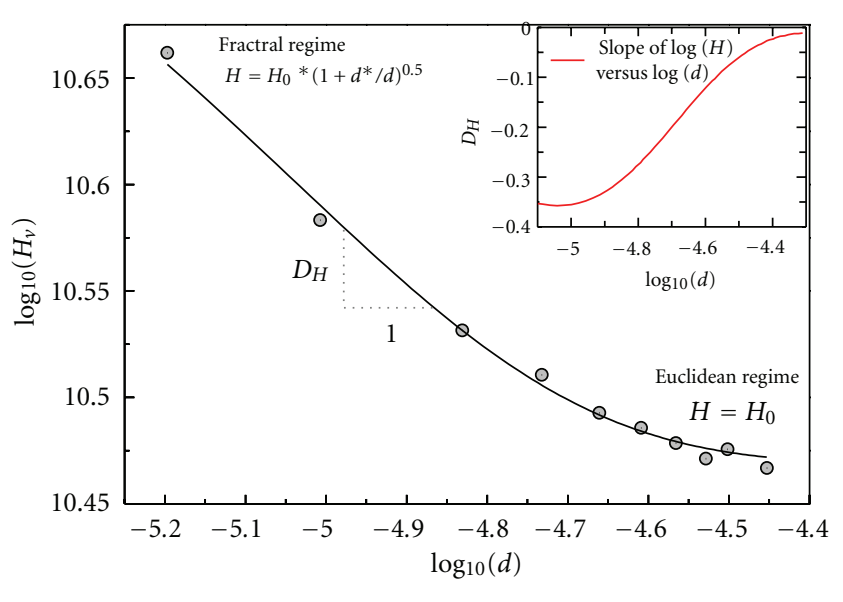

○ Experimental data

FIGURE 6: A bilogarithmic plot of the hardness calculated according to (5) plotted against the measured indentation diagonal length. The slope of the plot equals $D_{H}$, a fractal dimension for hardness with respect to $d$. In the insert, the fractal dimensional increment $D_{H}$ is plotted as a function of $\log d$. Nonlinearity of the scaling fractal dimensional suggests multifractal behaviour.

indentation size effect in hot-pressed $\mathrm{B}_{6} \mathrm{O}$. Further in-depth discussions on the fractal approach to indentation size effect are refereed to Carpinteri's comprehensive review on the subject [18].

On the basis of this approach, the multifractal scaling law (MFSL) for ISE can be written in the following analytical form:

$$
H_{v}=H_{\mathrm{mfsl}} \cdot\left(1+\frac{d^{*}}{d}\right)^{0.5}
$$

where $H_{\mathrm{mfs}}$ is the intrinsic hardness in the limit of infinite (a huge) applied load and $d^{*}$ is the critical material characteristic length which individuates the transition between the two regimes, that is, the fractal one and the nonfractal (Euclidean) one.

In order to study the fractal characteristic of the size effect dependence of microhardness depicted in Figure 2, a loglog plot of the Vickers microhardness and the indentation diagonal length was constructed based on the multifractal scaling law shown in (5) (and presented as Figure 6). The result shows that $\log H$ as a function of the $\log d$ is approximately linear in two parts of the scale dependence.

In this study, both $d^{*}$ and $H_{\mathrm{mfsl}}$ were determined simultaneously by means of nonlinear least squares analysis of the experimental data using Mathematica. $H_{\mathrm{mfs}}$ and $d^{*}$ were determined to be $28.9 \mathrm{GPa}$ and $1.41 \mu \mathrm{m}$, respectively. The fractal dimension in the first region can be depicted as the following equation.

The slope of the bilogarithmic plot shown in Figure 6 represents the fractal dimensional increment $D_{H}$, which is a measure of the variable influence of ISE on the measured Vickers hardness. The variation of fractal dimension of multifractality $D_{H}$ with $\log d$, as determined from $\log H$ versus $\log d$, is presented as an insert in Figure 6. Two limiting 
TABLE 2: A summary of the intrinsic microhardness values calculated according to Li and Bradt's PSR model, the Gong's MPSR model, and Carpinteri's MFSL model.

\begin{tabular}{ccccc}
\hline & $\begin{array}{c}H_{\mathrm{psr}} \\
(\mathrm{GPa})\end{array}$ & $\begin{array}{c}H_{\mathrm{mpsr}} \\
(\mathrm{GPa})\end{array}$ & $\begin{array}{c}H_{\mathrm{mfsl}} \\
(\mathrm{GPa})\end{array}$ & $\begin{array}{c}H_{\text {ave }} \\
(\mathrm{GPa})\end{array}$ \\
\hline Microhardness & $26.8 \pm 0.3$ & $28.2 \pm 0.3$ & $28.9 \pm 0.1$ & $28.0 \pm 0.3$ \\
\hline
\end{tabular}

conditions have to be satisfied: $D_{H}=0$ for large indents (Euclidean response) and $D_{H}=-0.5$ for small indents (multifractal behaviour). The last situation corresponds to the highest possible indentation size effect in hardness, which is a theoretical upper bound.

According to the insert in Figure 6, $D_{H}$ tends to zero and coincides with the occurrence in a crossover between fractal and Euclidean behaviour implying the progressive vanishing of fractality in the measured Vickers microhardness with increasing indentation load/size.

\section{Summary and Conclusions}

Figure 2 shows that the variation of $H_{v}$ with $P$ indicates that the hot-pressed $\mathrm{B}_{6} \mathrm{O}$ ceramic material exhibits ISE. Based on the observation, a comprehensive study of ISE in microhardness measurements of $\mathrm{B}_{6} \mathrm{O}$ was conducted using a number of existing models, that is, the classical Meyer's law, Li and Bradt's proportional specimen resistance model (PSR), the modified proportional specimen resistance model (MPSR), and Carpinteri's multifractal scaling law (MFSL). A summary of the hardness values calculated is shown in Table 2.

The average load-independent hardness of hot-pressed $\mathrm{B}_{6} \mathrm{O}$ from this study has been observed to be $28.0 \pm 0.3 \mathrm{GPa}$.

Based on the values of the PSR and MPSR parameters estimated by regression analysis, the origins of ISE in hotpressed $\mathrm{B}_{6} \mathrm{O}$ can be attributed to either the bulk material's indentation elastic recovery, the indenter/specimen friction resistance coupled with elastic resistance of the specimen, or/and the mixed elastic/plastic deformation response of material. The residual surface stresses' contribution to the observed ISE is observed to be negligible compared to the aforementioned.

The linear relationship of the double logarithm between measure (the microhardness) and scale (the applied load) shows indentation self-similarity, both in indentation shape and in the results of hardness. We can conclude this to be fractal behaviour. The load dependence of hardness shows dual fractal behaviour given the two different regions of hardness.

We can conclude and suggest that the variation of fractal dimension of multifractality $D_{H}$ with $\log d$ is a more resourceful indicator of the existence of ISE than the Meyer's index, for example.

\section{Acknowledgments}

The authors gratefully acknowledge the useful contributions of O. T. Johnson and the financial support from the
DST/NRF Centre of Excellence in Strong Materials and the University of the Witwatersrand Mellon Award.

\section{References}

[1] M. Herrmann, J. Raethel, A. Bales, K. Sempf, I. Sigalas, and M. Hoehn, "Liquid phase assisted densification of superhard $\mathrm{B}_{6} \mathrm{O}$ materials," Journal of the European Ceramic Society, vol. 29, no. 12, pp. 2611-2617, 2009.

[2] H. J. Kleebe, S. Lauterbach, T. C. Shabalala, M. Herrmann, and I. Sigalas, " $\mathrm{B}_{6} \mathrm{O}$ : A correlation between mechanical properties and microstructure evolution upon $\mathrm{Al}_{2} \mathrm{O}_{3}$ addition during hot pressing," Journal of the American Ceramic Society, vol. 91, no. 2, pp. 569-575, 2008.

[3] A. K. Suri, C. Subramanian, J. K. Sonber, and T. S. R. C. Murthy, "Synthesis and consolidation of boron carbide: a review," International Materials Reviews, vol. 55, no. 1, pp. 438, 2010.

[4] D. J. Roberts, J. Zhao, and Z. A. Munir, "Mechanism of reactive sintering of $\mathrm{MgAlB}_{14}$ by pulse electric current," International Journal of Refractory Metals and Hard Materials, vol. 27, no. 3, pp. 556-563, 2009.

[5] O. O. Kurakevych and V. L. Solozhenko, " $300 \mathrm{~K}$ equation of state of rhombohedral boron subnitride," Solid State Communications, vol. 149, no. 47-48, pp. 2169-2171, 2009.

[6] O. T. Johnson, I. Sigalas, E. N. Ogunmuyiwa, H. J. Kleebe, M. M. Müller, and M. Herrmann, "Boron suboxide materials with Co sintering additives," Ceramics International, vol. 36, no. 6, pp. 1767-1771, 2010.

[7] M. Herrmann, H. J. Kleebe, J. Raethel et al., "Field-assisted densification of superhard $\mathrm{B}_{6} \mathrm{O}$ materials with $\mathrm{Y}_{2} \mathrm{O}_{3} / \mathrm{Al}_{2} \mathrm{O}_{3}$ addition," Journal of the American Ceramic Society, vol. 92, no. 10, pp. 2368-2372, 2009.

[8] Z. Wang, Y. Zhao, P. Lazor, H. Annersten, and S. K. Saxena, "In situ pressure Raman spectroscopy and mechanical stability of superhard boron suboxide," Applied Physics Letters, vol. 86, no. 4, Article ID 041911, 2005.

[9] A. Andrews, M. Herrmann, T. C. Shabalala, and I. Sigalas, "Liquid phase assisted hot pressing of boron suboxidematerials," Journal of the European Ceramic Society, vol. 28, no. 8, pp. 1613-1621, 2008.

[10] R. Machaka, B. W. Mwakikunga, E. Manikandan, T. E. Derry, and I. Sigalas, "Raman spectrum of hot-pressed boron suboxide," Advance Matterial Letters, vol. 2, no. 1, pp. 58-64, 2011.

[11] A. Andrews, I. Sigalas, and M. Herrmann, "Boron suboxide composite material," WIPO Patent 2008132675, 2008.

[12] J. Gong, H. Miao, Z. Peng, and L. Qi, "Effect of peak load on the determination of hardness and Young's modulus of hot-pressed $\mathrm{Si}_{3} \mathrm{~N}_{4}$ by nanoindentation," Materials Science and Engineering A, vol. 354, no. 1-2, pp. 140-145, 2003.

[13] O. Şahin, O. Uzun, U. Kölemen, and N. Uçar, "Mechanical characterization for $\beta$-Sn single crystals using nanoindentation tests," Materials Characterization, vol. 59, no. 4, pp. 427434, 2008.

[14] H. Li and R. C. Bradt, "The effect of indentation-induced cracking on the apparent microhardness," Journal of Materials Science, vol. 31, no. 4, pp. 1065-1070, 1996.

[15] O. Şahin, O. Uzun, M. Sopicka-Lizer, H. Gocmez, and U. Kölemen, "Dynamic hardness and elastic modulus calculation of porous SiAlON ceramics using depth-sensing indentation technique," Journal of the European Ceramic Society, vol. 28, no. 6, pp. 1235-1242, 2008. 
[16] J. Gong, J. Wu, and Z. Guan, "Examination of the indentation size effect in low-load vickers hardness testing of ceramics," Journal of the European Ceramic Society, vol. 19, no. 15, pp. 2625-2631, 1999.

[17] J. Gong, J. Wu, and Z. Guan, "Analysis of the indentation size effect on the apparent hardness for ceramics," Materials Letters, vol. 38, no. 3, pp. 197-201, 1999.

[18] A. Carpinteri and S. Puzzi, "A fractal approach to indentation size effect," Engineering Fracture Mechanics, vol. 73, no. 15, pp. 2110-2122, 2006. 

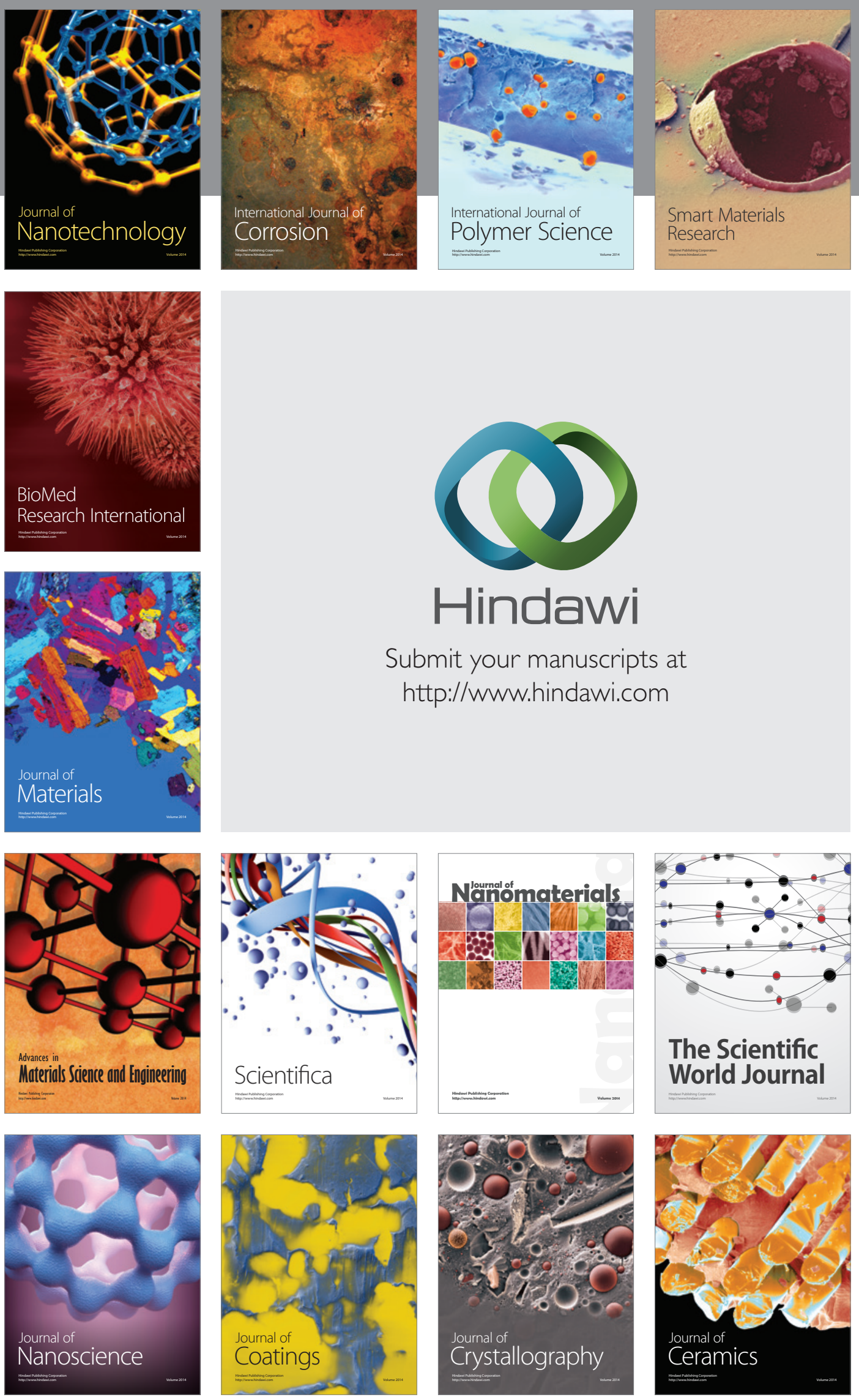

The Scientific World Journal

Submit your manuscripts at

http://www.hindawi.com

\section{World Journal}

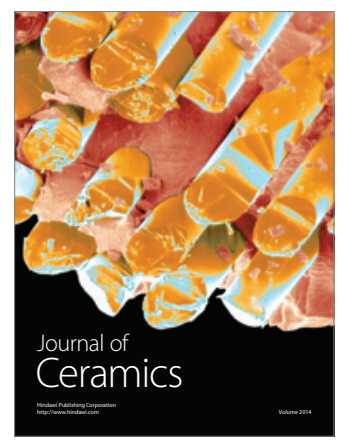

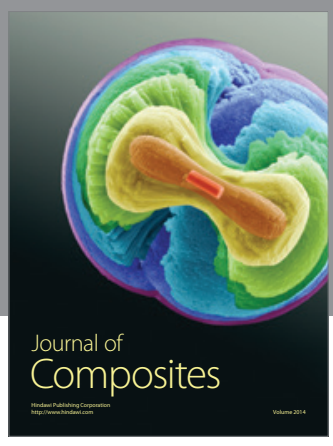
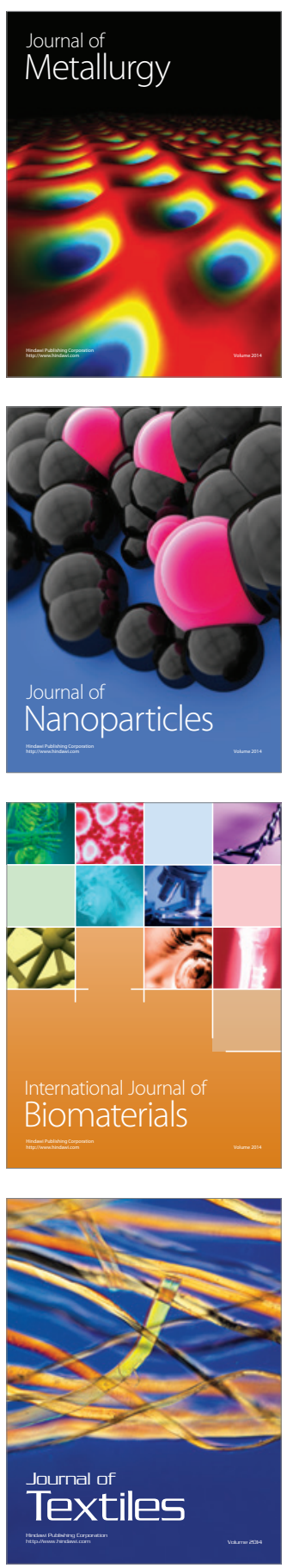